Letras, Lima. 1977-79. (Nos. 86-87), 5-16.

\title{
La Cultura Vicús - Hallazgos. y expresiones artísticas
}

marta LUISA saco

En la época en que la civilizarión Chavín, que abarcó gran parte del territorio del Perú dejó de ejercer su influjo dominante, floreció en la región del Norte la cultura Vicús, en cuyo arte se manifiestan ciertas cuialidades que alcanzaron su apogeo en el más importante estilo norteño, el estilo Mochica. En el de Vicús se observa, aunque en estado incípiente, la tendencia a la representación realista, el fuerte modelado escultórico y el carácter vital que hallamos en las expresiones artísticas Mochicas.

La cultura Vicús fue descubierta hace apenas dos décadas. En 1953, cerómica y objetos de oro de este estilo, que habían sido extraídos clandestinamente de los cementerios de Frías, en la provincia de Ayabaca, fueron decomisados porlia policía. Otros ejemplares fueron adquiridos por coleccionistas particulares. Se conocían en un principio con el nombre de Ayabaca, debido a que los primeros hallazgos se realizaron en este lugar; pero pronto se tuvo noticia de que el centro principal de la cultura en referencia no estaba en Ayabaca sino en la vecina provincia de Morropón y. particularmente, en la zona de Vicús, en la hacienda Pabur, propiedad de la familia Seminario Urrutia. Uno de los primeros arqueólogos que visitó dicha zona fue Ramiro Matos Mendieta, quien, en 1963, fue comisionado por el Patronato Nacional de Arqueología para verificar la procedencia de los huacos cuyo estilo era conocido con el nombre de Ayabaca. A ráz de su visita al yacimiento de Vicús, realizada el 29 de enero, y de las publicaciones referen. tes a ella, se cambió el nombre de estilo Ayabaca por el de Vicús (1).

(1) Matos Mendieta, Ramiro: Un nuevo estilo en la Arqueologir Peruana, La Industria, 30 de Enero, 1863: Algunas consideraciones sobre el estillo de Vicús, Revista del Museo Nacional, t. XXXIV, 1865-1866, págs. 91 y ss. 
La zona ar̃queológica de Vicús fue visitada nuevamente, en 1964, por Carlos Guzmán Ladrón de Guevara y José Casafranca, quienes fueron enviados por la Casa de la Cultura del Perú para realizar exploraciones y excavaciones en el lugar (2). Dicha zona está situada a 50 kilómetros al este de Piura $y$, aproximadamente, a la altura del kilómetro 1,074 de la carretera Panamericana Norte. Comprende dos sectores; uno de ellos es el llamado propiamente Vicús, el cual está situado cerca del caserío de este nombre y en las faldas orientales del cerro Vicús, perteneciente a la hacienda Pabur. El otro sector, denominado Yécala o El Ovejero, consiste en una serie de pequeñas colinas, que se hallan a una distancia de 6.50 kilómetros, hacia el sudeste del cerro Vicús. Guzmán y Casafranca, durante su permanencia en la zona, pudieron informarse de que allí, desde el año 1959, se había realizado excavaciones clandestinas en gran escala, dejando los cementerios en las faldas del cerro Vicús prácticamente agotados. Por ello llevaron a cabo sus excavaciones principalmente en el sector de Yécala o el Ovejero, el cual, aunque ya había sido excavado en parte, conservaba todavía algunas tumbas intactas. Además tuvieron referencia de que en este lugar se había encontrado ceramios Mochicas y algunos Chavinoides. Guzmán y Casafranca efectuaron también labores arqueológicas en un lugar cercano, llamado Lomas de Valverde, que queda al este del sector anteriormente citado y a un kilómetro de distancia.

En las excavaciones realizadas en Yécala o el Ovejero, extrajeron el contenido de 41 tumbas. Estas eran, en su mayoría, rectangulares; pero había álgunas que tènían uno prolongación lateral en su extremo inferior, adquiriendo la forma de una bota. Su profundidad variaba entre 4 a 15 metros aproximadamente. Se encontró algunas tumbas, en las cuales la parte superior estaba intacta, pero cuyo contenido había sido extraído por huaqueros, perforando un túnel desde una excavación vecina. En ninguna de las tumbas se halló el cadóver, revelándose su presencia sólo por un lente de arena, de color marrón oscuro, y por algunas piezas de la dentadura. Guzmán y Casafranca creen que esta desaparición del cadáver se debe a la presión a que ha estado sometido y a filtraciones de la lluvia. Cerca del citado lente de arena se descubrió ofrendas, consistentes principalmente en objetos de cerámica. En algunos casos se halló, junto con vasijas de estilo Vicús, algunas del período Mochica Inicial, o de características Chavinoides. Los objetos de metal hallados son, en su mayoría, de cobre; pero hay

(2) Casafranca, José y Guzmán Ladrón de Guevara, Carlos: Informe presentado al Patronato Nacional de Arqueología sobre los trabajos arqueológicos realizados en la zona de Vicús, departamento de Piura, Abril de 1964, (MS); Guzmán, Ladrón de Guevara, Carlos: Vicús, Enigma para Arqueólogos, Fanal, Vol. XXII, No. 83, Lima, 1967, págs. 21-26. 
algunos de oro o plata o enchapados en oro. Los tejidos se hallaIon sólo en fragmentos muy pequeños.

Además de los sitios-tipo Vicús y Yécala. hay otros yacimientos pertenecientes al complejo Vicús, en la provincia de Morropón, que han sido explorados por Ramiro Matos Mendieta (3). Uno de ellos es el de Pabur, al sur del caserío del mismo nombre. En este lugar hay tres montículos, dos de ellos con restos de ocupaciones tardías y un tercero en el que se ha hallado algunos tiestos Vicús con decoraciones blancas sobre fondo rojo y otros con ornamentaciones negativas. Hacia el sudeste de Pabur está Monte de los Padres. Llámase así un cerro y una quebrada ubicados a unos $32 \mathrm{ki}$ lómetros al sur de Chulucanas. En la vertiente noroeste del citado cerro se ha encontrado dos cementerios. Uno de ellos, según Matos, parece ser Mochica; el otro, Vicús. En este yacimiento se recogió fragmentos de cerámica Mochica y otros con decoración negativa o con ornamentaciones blancas sobre fondo rojo, pertenecientes al Complejo Vicús. Al sureste de monte de los Padres y dentro de la hacienda de este nombre, está el yacimiento de Talanqueras. Este consiste en un cementerio de alrededor 2 hectáreas de extensión, en el cual se encontró tumbas de gran profundidad en forma de bota o de pata de burro. Entre los ejemplares de cerámica Vicús, hallados en el lugar, predominaban los decorados con blanco sobre el rojo natural de la arcilla en relación a los de técnica negativa. Se ha encontrado, asimismo, ejemplares de los estilos Mo. chica I y Chavinoide tardío (Cupisnique Transicional). En Malamatanzas, situado al suroeste de Monte de los Padres, y a unos 2 kilómetros de Talanqueras hay otro cementerio perteneciente a la cultura Vicús, en el cual Matos recogió luna colección superficial que incluía cerámica Vicús Neqativo yoVicús Blanco sobre Rojo, así como Chavinoide (Cupisnique). Menciona también Matos otros sitios de ocupación Vicús como el Zapotal, situado al sur este de Malamatanzas y a un kilómetro al noreste de Morropón; y Piedras Gordas que se halla aproximadamente a 25 kilómetros al sur de Morropón. En Piedras Gordas se ha hallado, en una pequeña planicie, restos pertenecientes a las culturas Vicús y Mochica y algunos de la cultura Chimú.

En la provincia de Ayabaca, además del sitio ya mencionado de Frías, Matos ha ubicado otros yacimientos de la cultura Vicús, (4) entre ellos el llamado Callingara 3, que ocupa la parte central y noreste de la vertiente del cerro de este nombre y está situado a 17 kilómetros al noreste de Frías. Las tumbas, pertenecientes al Complejo Vicús, tienen forma de bota y no alcanzan gran profundidad. Los ceramios encontrados en el lugar son, en su ma-

(3) Matos Mendieta, Ramiro: op. cit. págs. 99-100.

(4) Matos Mendieta, Ramiro: op. cit.; págs. 96-97. 
yor parte, llanos. Algunos, sin embargo, están decorados con la técnica negativa y otros con motivos blancos pintados. Al sur de Callingara, a una distancia de 3 kilómetros, está el yacimiento de Santa Rosa, que también pertenece al Complejo Vicús y donde se ha encontrado cerámica modelada y figurativa con decoraciones, algunas de ellas hechas con pintura blanca y otras con técnica negativa. Al sur de Santa Rosa y a unos 10 kilómetros al oeste de Frías se halla el yacimiento de El Bronce, que está situado en la colina que se alza cerca de la casa-hacienda. Hay allí un cementerio semejante al de Callingara; Matos pudo observar dos vasijas escultóricas de estilo Vicús con decoraciones negativas, provenientes del citado cementerio.

Entre las manifestaciones artísticas de la cultura Vicús se destaca la cerámica. Sus formas, aunque no son muy variadas, presentan gran interés. Algunas de ellas muestran originalidad; otras, en cambio, se relacionan con formas predominantes en el Norte, o con las de algunos estilos del Sur, tales como los de Paracas y Nazca. Una forma vinculada con la cerámica norteña es un plato que descansa sobre un pedestal ancho y alto. Vasijas semejantes hallamos en el estilo Garbanzal del departamento de Tumbes. en la vasija Vicús el pedestal está decorado con la cabeza de un animal en ligero relieve. Sus ojos están formados por dos aberturas circulares y bajo ellos, en todo el contorno inferior del pedestal, hay cruces caladas. Estos motivos, lo mismo que las facciones del animal están contorneados por pintura blanca.

Otras formas consisten en vasijas globulares o troncocónicas de base curva, com cuello ancho y expandido que, a veces, están decoradas con un rostro humano (fig. I) o el rostro de un animal en ligero relieve. En un ceramio de este tipo hallamos la figura de un tigrillo. Hay también algunas vasijas abiertas, casi cilíndricas. Una de ellas está ornamentada con la cabeza, en alto relieve, de un animal monstruoso, en cuya enorme boca abierta se muestran amenazadores dientes. (5)

Algunos ceramios llevan en la parte superior un asa-canasta. En uno de ellos se ha trazado por medio de líneas blancas y gruesas, la cabeza de un buho, así como decoraciones geométricas. Los ojos y la nariz sobresalen en relieve y tienen forma de botones. Existen variantes entre las vasijas con asa-canasta, tanto en el asa, que puede ser cilíndrica o cintada, como en el cuerpo de la vasija que adopta diversas formas (6). En una vasija con asa-canasta; el cuerpo, decorado con una cabeza humana en relieve, está formado por una parte superior de lados curvos y una parte inferior

(5) Larco Hoyle, Rafael: La cerámica de Vicús. Lima 1965, fig. 23. (6) Larco Hoyle muestra ilustraciones de varios tipos de vasija con asa-canasta en las figs. 25,26 y 27 de su obra citada en la nota anterior. 


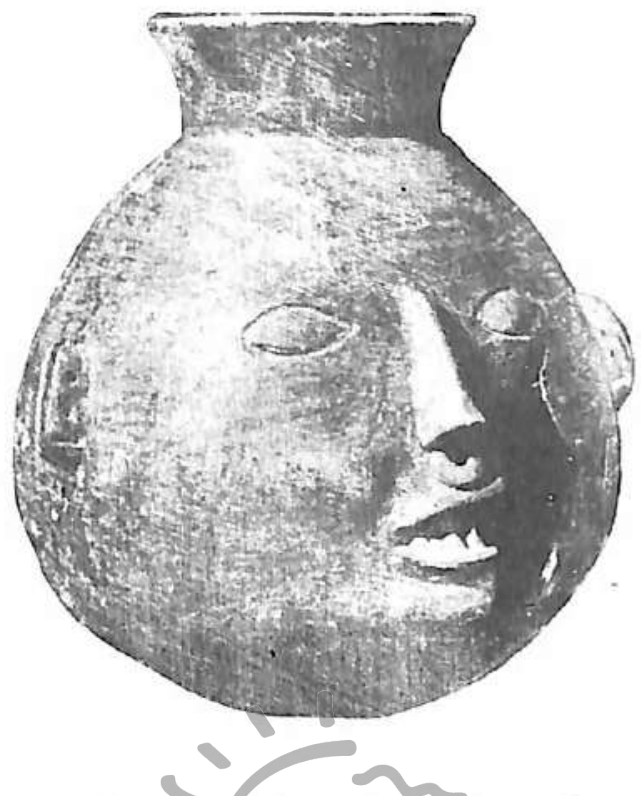

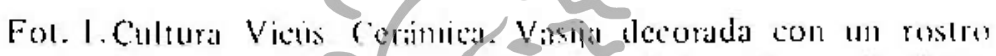
hamano en Gelieve llallada en Frias (Foro Cinilken)

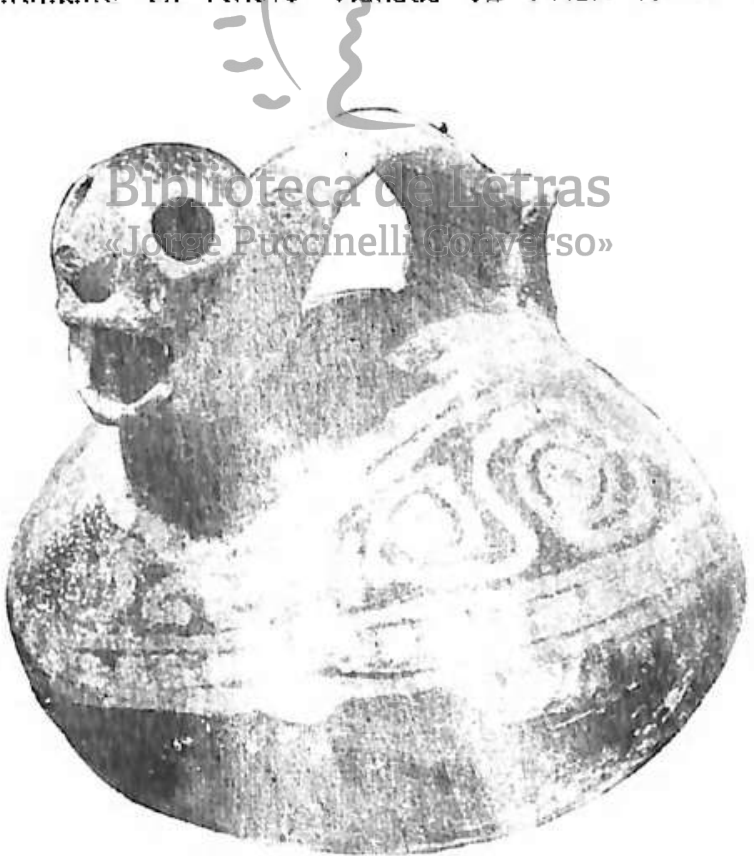

Fot. 2. Vasija globular cou ahe/d ke momo. pio y asal puente.

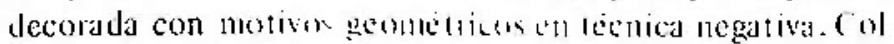
D. Seminario (Pitua) (i.uto (iuillen) 


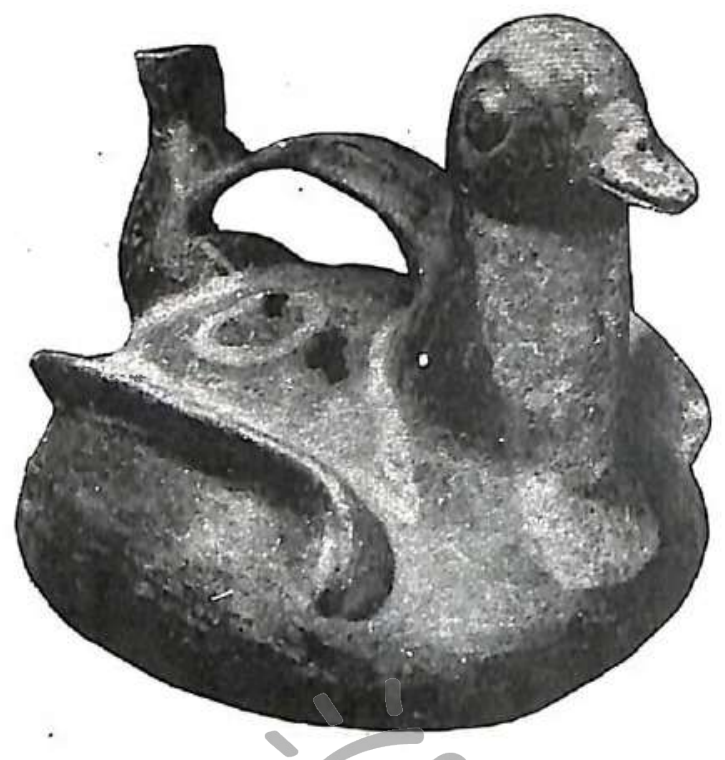

Fot. 3. Vasija en forma de pato. en la que la cabeza del animal está uniơa a un pico botelliforme por medio de un asa puente. Col. D. Seminario (Piura) (Foto Guillén).

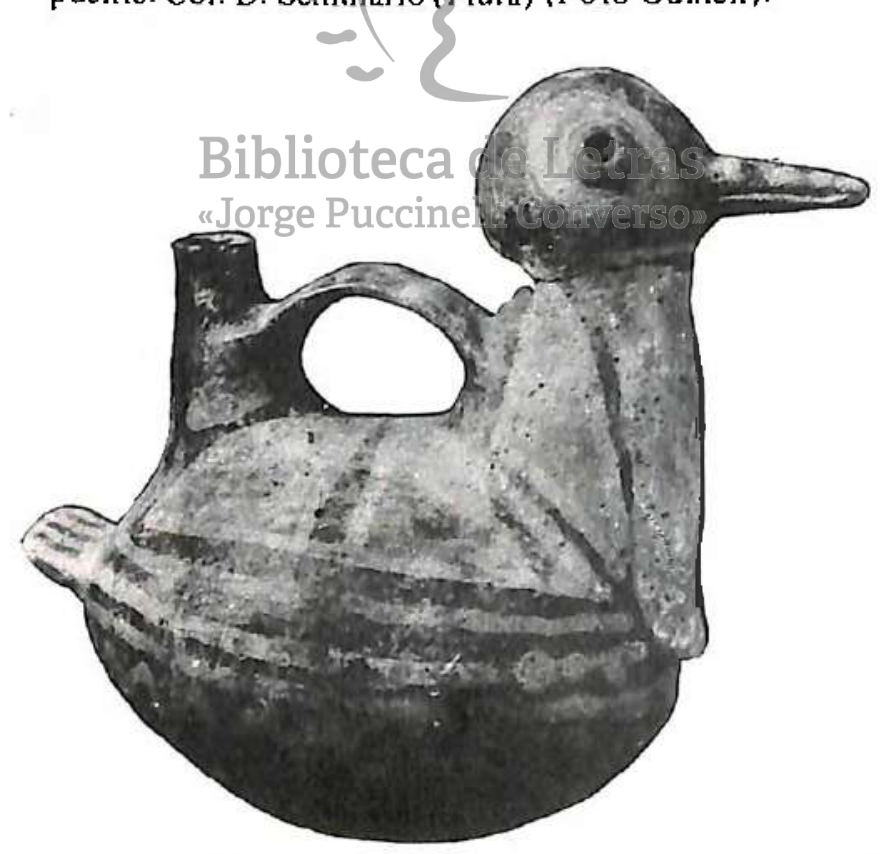

Fot. 4. Vasija en forma de ganso, semejante a la anterior. Col. D. Seminario (Piura) (Foto Guillén). 


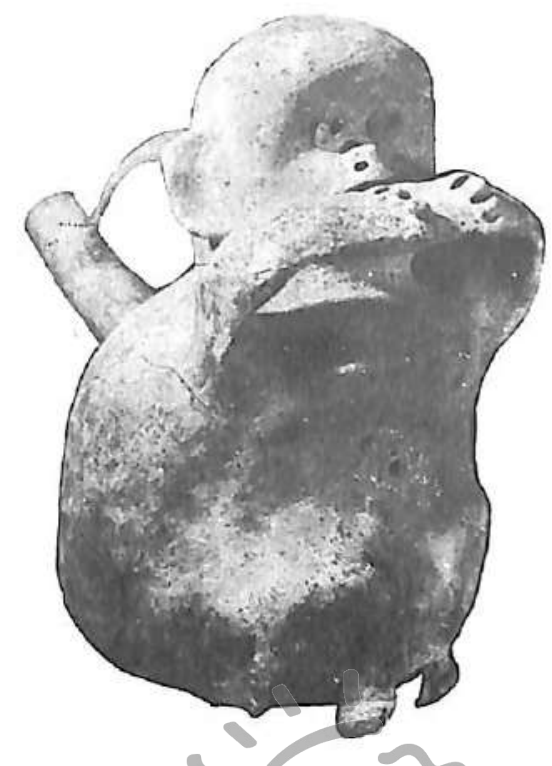

Fot. 5. Mono iocando un instrumenid. Museo Nacional ve Antropología y Arque ología (Folo Guillén)

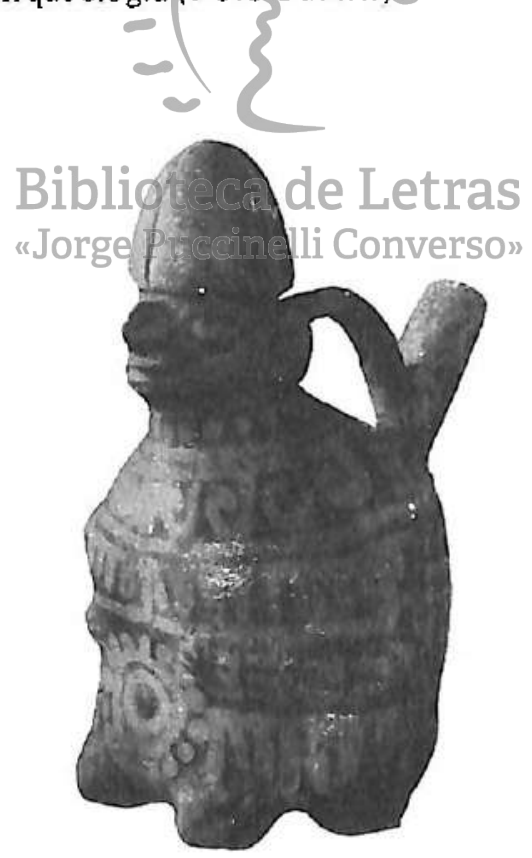

Fot.6. Personaje con gorro en forma de zapallo. con pico y asapuente en la espalda. Col D. Seminario (Piura) (Foro Gujllén). 


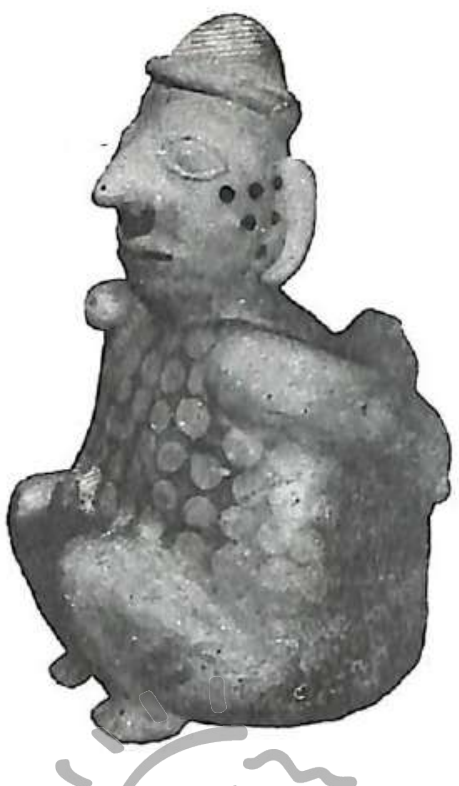

Fot. 7. Personaje con gor pe pueño y con perforaciones en el rostro. Col. D. Seminario (Piura) (Foto Guillén).

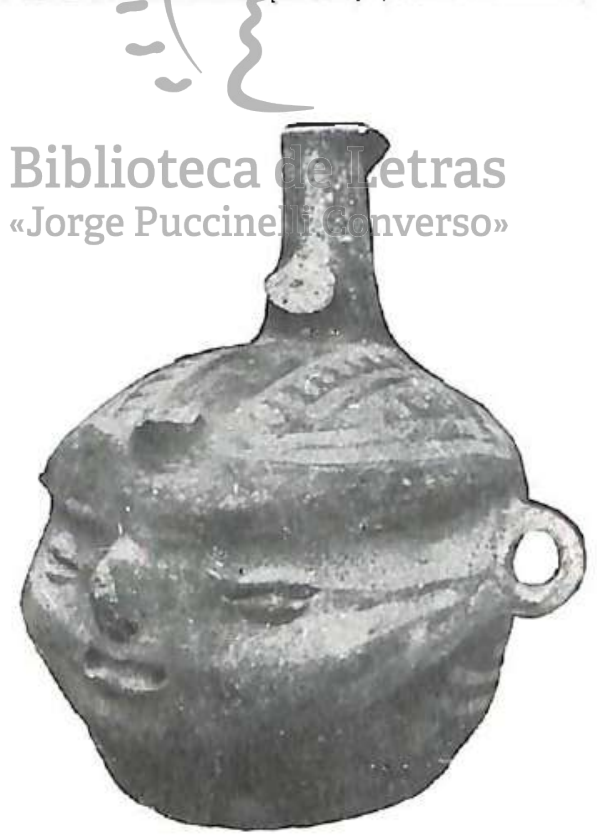

Fot.8. Vasija en forma de cabeza humana con pico en sa parte posterior del cráneo que se une a la frente por medio de un asa Hallada en Frías. (Foto Guillén). 


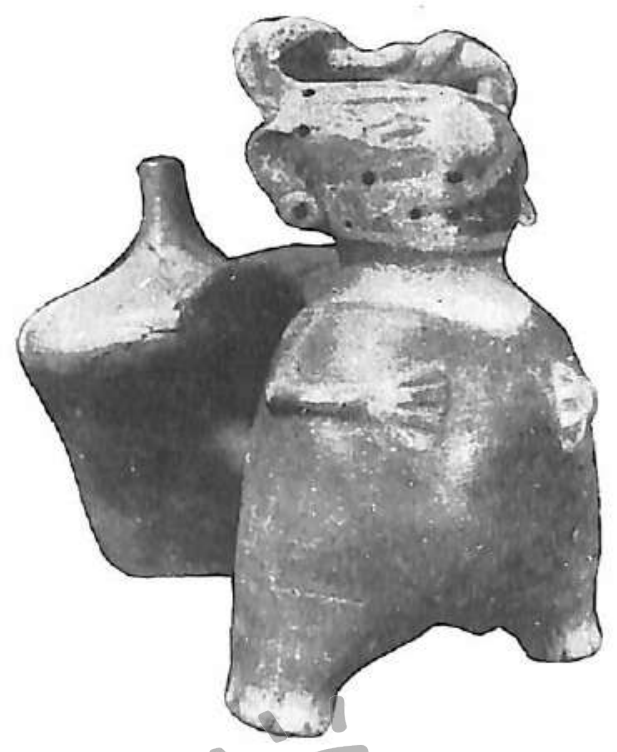

Fot.9. Vaso doble con personaje de nariz prominente y tocado de serpientes que se une/a una vasija botelliforme por medio de un tubo cilíndrico y un asa plana. (Foto Guillén).

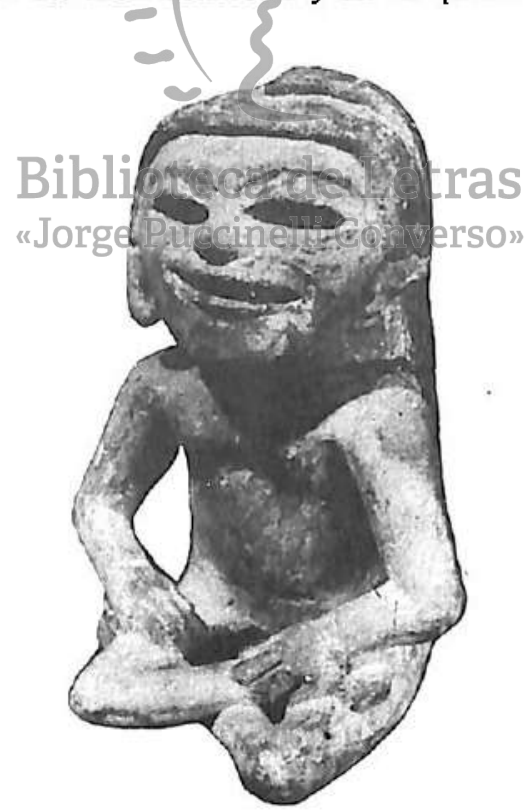

Fot. 10. Estatuilla sentada, de expresión sonriente. Hallada en Frias (Foto Guillén). 


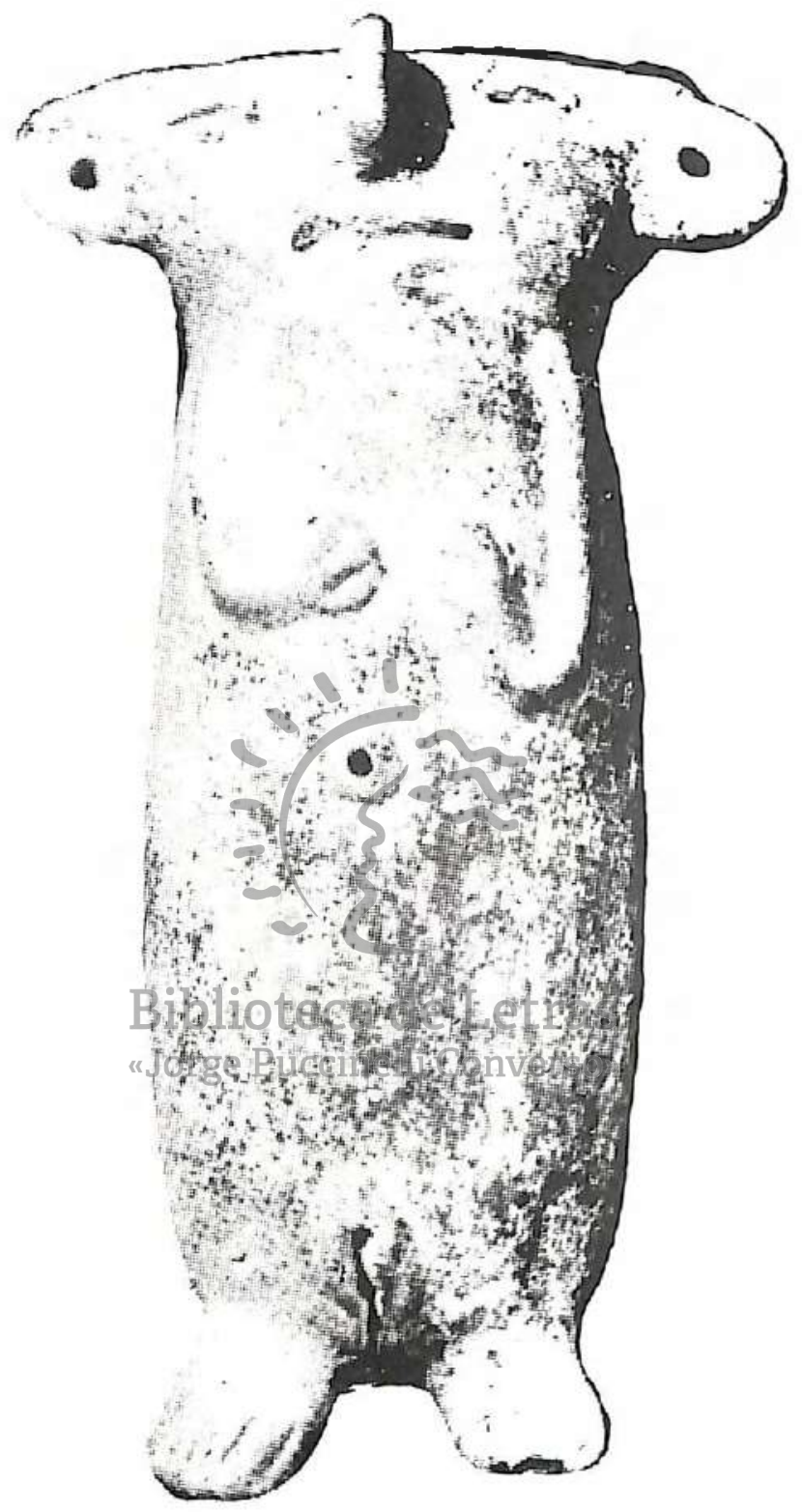

Fot. 11. Topo con rostro humano. Museo Nacionai de Antropología y Ar. queologia. (Foto Guillén). 
de perfil casi rcto. dando la impresión de dos recipientes superpuestos. Hay otros ceramios que están constituídos por tres secciones que se unen al centro en un cuerpo común, encima del cual se alza el asa-canasta. En una vasija de tipo similar, hay un núcleo central con asa-canasta y dos secciones laterales en forma de cabeza de felino.

Otro elemento que, como el asa-canasta, se usa en la superestructura de los ceramios, es el gollete asa-estribo que hallamos primero en la cerámica Chavín y también en la Mochica y en otros estilos cerámicos de la región del Norte. El gollete asa-estribo Vicús, a diferencia del gollete asa-estribo Chavín, de elaboración refinada, está ejecutado toscamente. El tubo arqueado presenta un aspecto irregular y el pico vertical es con frecuencia corto y no se separa claramente del tubo arqueado, formando ambos elementos una línea curva continua. Una vasija de este tipo tiene el cuerpo lenticular, el cual se encuentra ornamentado con la cabeza de una lechuza muy estilizada, formada por medio de dos bandas curvas en relieve que se unen en ángulo en uno de sus extremos. En el interior de estas curvas se sitúan los ojos. Otros ceramios con gollete asa-estribo presentan mayores elementos escultóricos (7). En uno de ellos, en el cuerpo de la vasija se ha representado un raión que está siendo devorado por una serpiente cienpiés. El otro es una vasija antropomorfa, en la cual uno de los extremos del tubo arqueado se adhiere al dorso de la figura y el otro extremo se recorta en parte para unirse a la cabeza.

Más a menudo, en las representaciones antropomorfas o zoomorfas, se coloca, en la parte posterior del cuerpo, un pico que se une a la cabeza de la figura por medio de un asa-puente. Este elemento constituído "porgcabezai, pico Go asa puente, lo encontramos también en la cerámica Gallinazo o Virú, que florece en el valle de Virú, al sur del valle de Moche, y en las culturas sureñas de Paracas y Nazca. No se puede determinar con certeza si esta forma se propagó de Sur a Norte o de Norte a Sur, pero es probable que su difusión se haya realizado en esta última dirección, pues según las informaciones obtenidas hasta ahora, el citado elemento aparece desde fecha más temprana en el Sur y se mantiene allí con mayor vigor durante largo tiempo. Es posible que después de la época de acogeo de la civilización Chavín, en la cual el Norte influyó poderosamente sobre el Sur, hubo una etapa en la que las culturas sureñas alcanzaron preponderancia $\mathrm{y}$ ejercieron influencia en las culturas norteñas, como las de Virú y Vicús. En la mayoría de las vasijas Vicús, en las que la cabeza se une a un pico por medio de una asa puente, el asa puente es plana; pero existen algunos ceramios en los que el asa es de media caña o cilíndrica

(7) R. Larco Hoyle: op. cit., figs, 12 y 4. 
como la que se emplea en el estilo Virú del valle de este nombre. El pico adopta también formas diferentes, pudiendo ser botelliforme, cilíndrico, acampanulado o ligeramente cónico y de altura y ancho variables. Las vasijas zoomorfas son más numerosas que las antropomorfas. En algunas de ellas, el cuerpo de la vasija se aproxima a la forma del animal representado, como en el caso de dos vasijas de pico botelliforme y asa plana que figuran respectivamente un pato y un ganso (figs. 3 y 4 ); en otras vasijas zooformas el cuerpo es globular (fig. 2) y a veces se apoya sobre un pedestal. En una vasija de este tipo (8) el pico está dirigido oblícuamente hacia un costado y hace ias veces de la cola del animal. Se ha encontrado también ceramios de cuerpo anular, en los cuales el pico se une por medio de un asa puente a dos cabezas de animal (9); y otros en los que el cuerpo del animal tiene la forma de una especie de calabaza, en la cual, en uno de los extremos, se alza la cabeza, que se une, por medio de un as a puente, a un boquete situado en el otro extremo (10). Existen varios ceramios con representaciones de monos, que llevan pico y puente en el dorso. En una vasija silbadora de este tipo, el animal aparece tendido y tiene los brazos apoyados en un cilindro (11); sus ojos muy expresivos consisten en dos pequeñas aberturas ovaladas. Otras veces se representa al mono erguido y lleva éste el pico y puente en la espalda, como algunas figuras antropomorfas. En una vasija de esta forma, el mono está sentado y tiene los dedos cruzados y los brazos, transformados en bandas planas, se levantan hasta la altura de la boca. El cuerpo está escasamente modelado (fig. 5).

Entre las vasijas antropomorfas con pico y puente en el dorso, hay una en la cual se representa a un personaje masculino que da la impresión de estar saliendo de una vásijalenticular y tiene las manos apoyadas sobre ella ( 1 la). de su espalda parte un asa plana que se une a un pico botelliforme situado en la parte posterior de la vasija lenticular. El personaje lleva un tocado en forma de rodete, su nariz, inmensamente larga, recuerda el pico de un ave. Los ojos están formados por dos prominencias alargadas con una ranura al centro. En este tipo de nariz y de ojos se encuentra en muchas vasijas antropomorfas del estilo Vicús. En otras vasijas se representa individuos sentados. En una de ellas (fig. 6) el personaje tiene la cabeza cubierta por un tocado en forma de medio zapallo, la nariz muy larga, y los ojos muy abiertos, de forma oval, contor-

(8) R. Larco Hoyle: op. ict., fig. 29.

(9) R. Larco Hoyle: op. cit. fig. 22.

(10) R Larco Hoyle: op. cit., fig. 21.

(11) Horkheimer, Hans: Vicús. Ed del Instituto de Arte. Contemporáneo, fig. en pág. 17, Lima, 1965.

(11a) Guzmán Ladrón de Guevara, Carlos: Vicús. Enigma para arqueólogos, Fanal, Vol. XXII, No. 83, 1967, figura en pág. 26. 
neados por ribetes, que se diferencian de los del personaje descrito anteriormente y que son también muy frecuentes en el estilo Vicús. El cuerpo, muy abultado, está decorado con bandas y volutas; los brazos apenas se señalan en relieve y las piernas están reducidas a muñones. En el dorso se alza un pico tubular que se une a la cabeza de la figura por medio de un asa cilíndrica. En una vasija semejante, el personaje tiene en el dorso un as que se une a un pico grueso acampanulado; lleva un gorro semiesférico y orejeras discoidales y algunos adornos de su vestimenta están trazados por medio de incisiones (12). Hay otras vasijas antropomorfas que representan un personaje que lleva una especie de cántaro en la espalda. En una vasija silbadora de este tipo, el asa-puente que unía el cántaro a la cabeza de la figura ha desaparecido. El personaje de nariz larga y ojos ovalados contorneados por un ribete, tiene un gorro casi cónico que tal vez sea indicio de una deformación craneana (fig. 7). Las orejas ocupan casi toda la altura de la cara y delante de ellas, a cada lado, hay seis perforaciones, las cuales había en el interior de la cabeza, al llenarse la vasija con líquido, salía el aire por las perforaciones y se producía el sonido. Esta abundancia de huecos para la salida del aire es característica de las vasijas silbadoras de estilo Vicús. El personaje del ceramio en referencia tiene los brazos hacia atrás como si estuviera sujetando el cántaro que lleva a la espalda. En el cuerpo se advierte una decoración de círculos, hecha en técnica negativa, destacándose los círculos en el color rojo de la arcilla sobre un fondo pintado de negro. Hay otra vasija escultórica muy interesante en la cual, en la parte delantera, se halla un personaje sentado sobre un animal bicéfalo, arqueado, cuyas cabezas se acercan a su rostro como para comunicarle algo. Horkheimer ha denominado a esta representación "El Gran Secreto" (13). Existen ceramios antropomorfos de estilo Vicús, con pico y puente, en los que no se representa al personaje de cuerpo entero, sino sólo la cabeza. (14) En estas vasijas el pico se coloca en la parte superior y de allí parte el asa, terminando cerca de la frente (fig. 8) o en la parte posterior del cráneo.

Un grupo de formas muy característico de Vicús lo constituyen las vasijas dobles. El tipo de vasija doble más frecuente consiste en una representación antropomorfa, que se une a un recipiente en forma de botella, por medio de un asa puente y de un tubo cilíndrico (fig. 9). Los personajes representados son masculinos o femeninos y, algunas veces, hermafroditas. Todos ellos tienen el cuerpo desproporcionado, la frente estrecha, enormes orejas y narices largas como pico de ave. Los ojos son semejantes a los de

(12) R. Larco Hoyle: La cerámica de Vicús, 1965, carátula.

(13) H. Horkheimer: op. cit., pág. 4.

(14) R. Larco Hoyle: La cerámica de Vicús ... 1965, figs. 1 y 2. 
otras representaciones escultóricas del estilo Vicús. Generalmente son ovalados y están formados por abultamientos con una ranura al centro, o están muy abiertos y contorneados por un ribete. El tocado y otros elementos de los personajes varían. Una figura masculina, que representa un guerrero, lleva un gorro cónico y un escudo. Oira figura del mismo tipo tiene, alrededor del cuello, un collar formado por cabezas trofeo $\mathrm{y}$, en la cabeza, una especie de corona. Un tocado en forma de corona hallamos también en un personaje hermafrodita. Las figuras femeninas llevan, a veces, trenzas o gorros sencillos semiesféricos. En una de ellas hay, además, un aplanamiento de la cabeza, que probablemente indica una deformación craneana (15). Entre las vasijas dobles con personaje antropomorfo existen variantes. Hay un ejemplar en el que la botella y el personaje, unidos por un as a puente, están situados sobre un recipiente cuadrangular (16).

En las vasijas dobles, hay algunas en que la representación antropomorfa se reemplaza por la figura de un animal. En ciertos casos se da una forma diferente a la segunda vasija. Cuando se usa figuras escultóricas de animales, éstos se sitúan sobre recipientes en forma de fruto o de otra índole. En una vasija de esta clase se ha colocado al animal encima de una calabaza (17); en otro ceramio se ha representado a un mono sobre un recipiente casi cilíndrico, que se une a otro recipiente del mismo tipo, por medio de un tubo y de la cola del animal, la cual reemplaza al asa puente. En otros casos, la vasija principal tiene forma de casa o templo (18) y, en su interior, hay, a veces, uno o varios personajes. Otras vasijas dobles son de carácter fitomorfo. Una de ellas está formada por dos calabazas con pico y puente.

Se ha encontrado también estatullias de cerámica pertenecientes al estilo Vicús. Algunas, que representan seres humanos, se hallan en actitudes muy naturales (fig. 10); otras, en cambio, son algo rígidas y tienen la cara excesivamente ancha (19). Hay también figurillas de animales, y vasijas de esta forma, algunas con caracteres antropomorfos, como por ejemplo la de un topo con rostrohumano (fig. 11) o la de una rana. Si bien algunas figuras antropomorfas o zoomorfas de estilo Vicús dan la impresión de que en ellas

(15) Varios tipos de vasijas dobles antropomorfas están ilustrados en Horkiheimer, op. cit., frontispicio y pág. 16; Guzmán, op. cit., págs. 24 y 26; Larco, op. cit., figs. 8 y 10.

(16) Una vasija de este tipo, perteneciente a una colección particular fue exhibida en Lima, en la Galería del Banco Continental en 1966,

(17) R. Larco Hoyle: op. cit., fig. 11.

(18) Vasijas dobles con representaciones de animales o de templos, pertenecientes a la colección de Domingo Seminario de Piura, fueron exhibidas en Lima, en la Exposición de Arte Prehispánico que se inauguró en el Museo de Arte en mayo de 1966.

(19) R. Matos: op: cit., lám. 7. 
la fuerza vital estuviese en suspenso, como si se hallase sumidas en profundo sueño, en otras se manifiesta plenamente la vida, y sus miradas expresan alegría, asombro o temor. Al contemplarlas nos parece que revive ante nosotros ese lejano mundo desaparecido.

Algunas vasijas Vicús, de los diversos tipos descritos, son monoctomas y estám recubiertas de engobe rojo; pero es más frecuente que la superficie del ceramio se decore con ornamentos geométricos en técnica negativa. Cuando se usa esta técnica, se emplea, a menudo, pintura negra para el fondo, destacándose las decoraciones en el color natural de la arcilla. La técnica negativa se usa también en la cerómica Virú, en la de Paracas Cavernas y en otras culturas del Antiguo Perú. Aunque adquiere gran desarrollo en el Norte, especialmente en la cultura Huaylas o Recuay, parece ser de origen surño, pues en el Sur donde se ha hallado sus primeras manifestaciones. Los ejemplos más antiguos de esta técnica en el Perú los encontramos en la cerámica de Hacha, en Acarí, en el departamento de Arequipa, la cual pertenece al período inicial. En otras vasijas Vicús se emplea la técnica positiva, delineando los motivos con pintura blanca sobre la superficie roja del ceramio. La pintura, tanto positiva como negativa, ha sido colocada antes o después de la cocción de la vasija, presentando, en este último caso, un carácter impermanente. Los motivos geométricos que se emplea en la técnica negativa son muy semejantes a los que se usa en la técnica positiva. Consisten principalmente en ángulos, círculos concéntricos, volutas, signos escalonados, bandas rectas paralelas o bandas onduladas (20).

Varios fechados radiocarbónicos para la cerámica Vicús han sido obtenidos por Homs D. Disselhoffe Oscilan entre 250 y 650 d.C.

(20) En la zona de Vicús se ha hallado algunos vasos relacionados con el estilo Vicús $\mathbf{y}$ con el estilo Mochica. Tienen una técnica depurada, semejante a la de las vasijas Mochicas; pero hay en ellos algunos elementos del estilo Vicús. La mayoria representa animales, especialmente aves, que llevan en el dorso un pico largo cónico y un asa puente cilindrica. Existen también algunas vasijas que, en vez de pico y asa-puente, tienen en la parte superior un gollete asa-estribo, semejante al de los ceramios de los primeros tiempos del estilo Mochica. Se encuentra asimismo algunas vasijas dobles. Una de ellas, consiste en una vasija botelliforme, que se une, por medio de un asa puente cilíndrica, a un recipiente, de cuyo interior emerge la cabeza de un ave. Las vasijas en referencia están, generalmente, recubiertas de un engobe naranja $y$, en ellas, algunos elementos se trazan por medio de incisiones; se usa, sin embargo, en ciertos casos, en vez de incisiones, pintura de color crema. Larco Hoyle llama a estas vasijas "Anaranjadas" y opina que son anteriores al estilo Mochica. Ramiro Matos, en cambio, considera, y muy justamente, que son una variante del estilo Mochica y las llama "Mochica Anaranjado" (Larco Hoyle, La Cerámica de Vi. cús, Lima 1965, págs. 11 y 33 figs. 34 y 37; Matos Mendieta, Ramiro: Algunas consideraciones sobre el estilo de Vicús, Revista del Museo Nacional, t. XXXIV, Lima 1965-66, pág. 111). 
y provienen de tumbas que excavó en el sector de Yécala en 1966 (21), las cuales contenían vasijas Vicús. Dichos fechados, sin embargo, no indican en forma definitiva la época en que floreció la cultura Vicús. Son pocas las excavaciones científicas realizadas en yacimientos de la citada cultura $y$, por lo tanto, es posible que nuevos hallazgos señalen una fecha más temprana para los comienzos del estilo Vicús.

Los hallazgos de objetos de metal han sido numerosos en la zona de Vicús. Pocos objetos, sin embargo, son de oro. En la mayoría se usa el cobre, ya sea puro o con un ligero enchape de oro. Según Carlos Guzmán, en las cámaras funerarias más profundas se ha hallado un mayor número de objetos de oro, especialmente narigueras, tempetas y cuentas de collar. En las excavaciones realizadas por él y Casafranca en 1964, en Yécala o el Ovejero, en el sector que denominaron Vicús IV, hallaron, en la tumba más importante, situada a gran profundidad, la número 11, una cuenta de collar y dus narigueras de oro, así como dos narigueras de plata y varios objetos de cobre, algunos de ellos enchapados (22).

En las exploraciones que realizó en Piura, en 1963, Ramiro Matos pudo observar, en las colecciones piuranas, una gran cantidad de objetos de metal procedentes de las tumbas de Vicús. La mayoría era de cobre o de cobre enchapado de oro; pero había algunos objetos de oro; o de plata y piedras preciosas como lapislázuli, cuarcita y turquesa. Consistían principalmente en orejeras, diademas, narigueras, pectorales y placas de diversos tipos, decoradas con motivos antropomorfos y zoomorfos, en las cuales había orificios que servían para coserlas en los vestidos. Había también vasos de metal de variadas formas, como keros, copas o cuencos. Algunos de estos vasos estaban lornamentados con motivos hechos en la técnica del repujado (23).

Entre los objetos hallados en las iumbas de Vicús, destacan de manera especial las narigueras. La mayoría tiene forma de me-

(21) Disselhoff no encontró ningún ceramio Mochica. Las muestras obtenidas fueron analizadas en el laboratorio del Needersächsisches Ani für Bodenforschung" en Hannover e indicaron respectivamente las fechas de $250 \pm 150$ D.C., $410 \pm 60$ D.C., $425 \pm 115$ D.C. $460 \pm 70$ D.C. y $653 \pm 100$ D.C.; Disselhoff, $\bar{H}$. D., Seis fechas radiocarbónicas de Vicús, Actas del XXXIII Congreso Internacional de Americanistas, Part I, Munich, 1969, págs. 341-345.

(22) Guzmán Ladrón de Guevara, Carlos: op. cit., págs. 25 y 26; Casafranca, José y Guzmán Ladrón de Guevara, Carlos: Informe presentado al Patronato Nacional de Arqueologia sobre los trabajos arqueológicos realizados en la zona de Vicús, departamento de Piura. Abril de 1964 (MS).

(23) Matos Mendieta, Ramiro: Algunas consideraciones sobre el estilo Vicús, Revista del Museo Nacional, tomo XXXIV, Lima 1965-66, pág. 123. 
dia luna. En ellas hay en el centro del borde superior, una pequeña romura y un orificio circular que servían para sujetarlas en la nariz. Otras narigueras tienen forma de luna creciente. Son de tamaños muy diversos $\mathrm{Y}$ frecuentemente están ornamentadas con pequeñas prominencias semiesféricas, hechas en la técnica del repujado. Hay, sin embargo, otras narigueras decoradas con motivos figurativos, como, por ejemplo, el rostro de una divinidad. Algunas están ornamentadas con cuentas y laminillas triangulares de oro. Ciertos personajes representados en la cerámica llevan narigueras cuyas formas son semejantes a las de metal. Se ha encontrado también cuencos de oro, con un alto porcentaje de cobre, decorados algunos de ellos con figuras humanas o de animales (24).

No se ha descubierto hasta el momento tejidos ni restos arquitectónicos importantes pertenecientes al estilo Vicús. La cerámica y la orfebrería constituyen las principales expresiones artísticas de esta remota cultura, que se extendió en parte de la zona norte del Perú, y nos hablan del carácter vital y de las costumbres del pueblo que las creó.

\section{BIBLIOGRAFIA}

CASAFRANCA, José y GUZMAN LADRON DE GUEVARA, Carlos: 1964 Informe presentado al Patronato Nacional de Arqueologia sobre los trabajos arqueológicos realizados en la zona de Vicús (MS).

DISSELFOFF, Fans D.:

1969 Seis fechas radiocarbónicas de Vicús Actas del XXXII Congreso Internacional de Americanistas, Part. I, Munich.

GUZMAN LADRON DE GUEVARA, Carlos:

1967 Vicús, Enigma para arqueólogos, Fanal, Vol. XXII, No. 83, Lima.

HORKHEIMER, Hans:

1965 Vicús. Ed. del Instituto de Arte Contemporáneo, Lima.

(24) Un buen número de narigueras de los tipos descritos y varios cuencos de oro pertenecientes a la colección de Domingo Seminario, de Piura, fueron exhibidos en la citada Exposición de Arte Prehispánico del Museo de Arte de Lima, inaugurada en Mayo de 1965; y en la Exposición de la Galería del Banco Continental, realizada en 1966. - En Vicús se ha hallado también varios objetos de metal pertenecientes al estilo Mochica. Uno de los más característicos es la cabeza de un zorro, de cuyas orejas cuelgan pendientes discoidales, que es muy semejante a una cabeza de zorro encontrada en la Huaca de la Luna en Moche. (Horkheimer, Hans: Vicús. Instituto de Arte Contemporáneo, Lima 1965, pág. 21). 
LARCO HOYLE, Rafael:

1965 La cerámica de Vicús, Lima.

1966 La cerámica de Vicús y sus nexos con las demás culturas, Lima.

MATOS MENDIETA, Ramiro:

1963 Un nuevo estilo en la Arqueología peruana, La Industria, 30 de Enero.

1965-66 Algunas consideraciones sobre el estilo de Vicús, Revista del Museo Nacional, T. XXXIV, Lima.

MEJIA XESSPE, Toribio:

1965-66 Algunas noticias sobre las tumbas precolombinas de Vicús Piura, Revista del Museo Nacional, t. XXXIV, Lima.

1965-66 Técnica negativa en la decoración de la cerámica peruana, Revista del Museo Nacional, t. XXXIV, Lima.

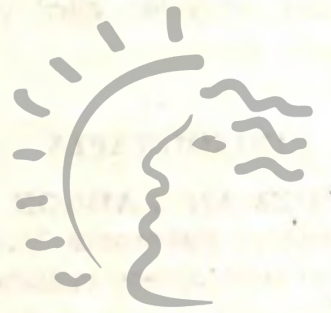

Biblioteca de Letras "Jorge Puccinelli Converso" 